\title{
PROSES PELAKSANAAN ASUHAN KEPERAWATAN DAN KAITANNYA DENGAN KEPUASAN PASIEN
}

\author{
Audina Tio Junianti Manik \\ audina.junianti@gmail.com
}

\section{Latar Belakang}

Asuhan keperawatan merupakan kegiatan yang wajib diketahui dan dikuasai oleh setiap perawat.

Dan asuhan keperawatan pun memiliki SOP (Standar Operasional Prosedur) yang menjadi pedoman agar kegiatan pelayanan terlaksana dengan baik dan benar. Standar ini lah yang menggambarkan nilai profesi keperawatan dan memperjelas apa yang diharapkan dari profesi keperawatan.

Asuhan keperawatan adalah suatu pendekatan untuk pemecahan masalah yang memampukan perawat untuk mengatur dan memberikan asuhan keperawatan. Standar asuhan yang tercantum dalam Standar Praktik Klinis Keperawatan terdiri dari lima fase asuhan keperawatan: 1) Pengkajian; 2) Diagnosa; 3) Perencanaan; 4) Implementasi; dan 5) Evaluasi... ${ }^{[1]}$

Proses keperawatan adalah suatu cara atau metode yang sistematis dalam memberikan asuhan keperawatan yang dilakukan oleh perawat dan bekerjasama dengan pasien (induvidu, keluarga, masyarakat) yang bertujuan untuk mengidentifikasi masalah keperawatan dengan melakukan pengkajian, menentukan diagnosa, merencanakan tindakan yang akan dilakukan, melaksanakan tindakan serta mengevaluasi hasil asuhan keperawatan yang telah diberikan dengan berfokus pada pasien, berorientasi pada tujuan yang telah ditetapkan bersama. ${ }^{[2]}$

Proses asuhan keperawatan secaara umum adalah untuk meningkatkan kualitas asuhan keperawatan dalam pelayanannya. Tujuan khusus dari proses keperawatan adalah mengidentifikasi masalahmasalah terkait kebutuhan dasar manusianya klien, menentukan diagnose keperawatan, menyusun perencanaan keperawatan yang tepat untuk mengatasi diagnosa keperawatan, terlaksananya tindakan-tindakan keperawatan secara tepat dan terencana, mengetahui perkembangan klien, serta menentukan tingkat keberhasilan asuhan keperawatan itu sendiri. ${ }^{[2]}$

Proses keperawatan sendiri memiliki sifat, yaitu terbuka dan fleksibel, dilakukan melalui pendekatan individual, penanganan masalah yang terencana, mempunyai arah dan tujuan, merupakan siklus yang saling berhubungan, terdapat validisasi data dan pembuktian masalah.

Seperti yang disebutkan sebelumnya, bahwa proses keperawatan ini meningkatkan kualitas 
asuhan keperawatan dalam pelayanannya.

Peningkatan kualitas ini juga bergantung kepada kepuasan klien atas pelayanan perawat. Menurut Gerson (2002), untuk mengetahui tingkat kepuasan pelanggan dapat diklasifikasikan dalam beberapa tingkatan sebagai berikut : 1 . Sangat memuaskan, diartikan sebagai ukuran subjektif hasil penilaian perasaan pasien yang menggambarkan pelayanan kesehatan sepenuhnya atau sebagian besar sesuai kebutuhan atau keinginan pasien, seperti sangat bersih (untuk prasarana), sangat ramah (untuk hubungan dengan dokter atau perawat), atau sangat cepat (untuk proses administrasi), yang seluruhnya menggambarkan tingkat kualitas pelayanan yang paling tinggi. 2. Memuaskan, diartikan sebagai ukuran subjektif hasil penilaian perasaan pasien, yang menggambarkan pelayanan kesehatan tidak sepenuhnya atau sebagian sesuai kebutuhan atau keinginan seperti tidak terlalu bersih (untuk sarana), agak kurang cepat (proses administrasi), atau kurang ramah, yang seluruhnya ini menggambarkan tingkat kualitas yang kategori sedang. 3. Tidak memuaskan, diartikan sebagai ukuran subjektif hasil penilaian perasaan pasien rendah, yang menggambarkan pelayanan kesehatan tidak sesuai kebutuhan atau keinginan seperti tidak terlalu bersih (untuk sarana), agak lambat (untuk proses administrasi), atau tidak ramah. 4. Sangat tidak memuaskan, diartikan sebagai ukuran subjektif hasil penilaian perasaan pasien yang rendah, menggambarkan pelayanan kesehatan tidak sesuai kebutuhan atau keinginan seperti tidak bersih (untuk sarana), lambat (untuk proses administrasi), dan tidak ramah. Seluruh hal ini menggambarkan tingkat kualitas yang kategori paling rendah. ${ }^{[1]}$

Untuk mencapai hasil kepuasan yang sangat memuaskan dan memuaskan dari klien, diperlukannya pelayanan yang serius dengan cara menerapkan proses asuhan keperawatan yang baik dan benar.

Dari pernyataan diatas, penulisan ini bertujuan untuk membantu perawat terutama kepada calon perawat atau mahasiswa keperawatan apa saja yang berkaitan dengan proses asuhan keperawatan.

\section{Metode}

a) Didalam penulisan ini, saya menggunakan metode menganalisis dengan cara mengumpulkan beberapa jurnal e-book dari internet, membacanya, dan juga mengkompilasi isi dari berbagai jurnal serta $e$-book tersebut.

b) Diambil dari dua jurnal sebagai referensi. Yang pertama diambil dari jurnal dengan judul "PENERAPAN ASUHAN KEPERAWATAN PELAKSANA DI RUMAH SAKIT BANDA ACEH', oleh Husnul Wirdah dan Muhmmad Yusuf. Metode yang digunakan dalam penilitian mereka adalah deskriptif dengan desain 
cross sectional study. Teknik

pengumpulan data adalah dengan

wawancara terpimpin yang dikaksanakan

pada tanggal 18-21 Juli 2016, di Ruang

Rawat Inap Rumah Sakit Umum Daerah

Meuraxa Banda Aceh. Sampel dalam

penilitian ini berjumlah 58 orang. Uji

analisa data yang dilakukan adalah

univariate.

Yang kedua dari jurnal yang berjudul

"KINERJA PERAWAT DALAM

MEMBERIKAN ASUHAN

KEPERAWATAN BERPENGARUH

TERHADAP KEPUASAN PASIEN

RAWAT INAP" oleh Khamida dan

Mastiah. Metode yang digunakan dalam

penelitian mereka adalah penelitian survei

analitik dengan pendekatan cross sectional.

Teknik Sampling dalam penelitian ini

adalab Probability Sampling dengan

teknik Simple Random Sampling, dan

sampel pada penelitian ini adalah pasien

sebanyak 39 orang yang dirawat di Ruang

Multazam Rumah Sakit Islam Surabaya.

\section{Hasil}

\section{Metode Jurnal Pertama}

Berdasarkan data yang didapat dari jurnal yang ditulis oleh Husnul Wirdah dan Muhmmad Yusuf, disimpulkan bahwa kategori umur responden sekitar 31-40 tahun, jenis kelamin responden sebagian besar adalah perempuan (35 orang), pendidikan terakhir responden sebagian besar adalah DIII Keperawatan dengan jumlah 42 orang,status pekerjaan responden terbanyak adalah Non PNS dengan jumlah 36 orang, dan pengalaman kerja responden yaitu 33 orang pada kategori 5-10 tahun.

Penilaian penerapan asuhan keperawatan oleh peneliti terhadap perawat pelaksana dinilai secara terpisah.penerapan asuhan keperawatan terdiri dari beberapa komponen, yaitu : pengkajian keperawatan, diagnose keperawatan, perencanaan keperawatan, implementasi dan evaluasi keperawatan. Berdasarkan hasil analisis penerapan asuhan keperawatan oleh perawat pelaksana di ruang rawat inap Rumah Sakit Umum Daerah Meuraxa kebanyakan pada kategori baik. Dengan hasil penelitian data Pengkajian Keperawatan yang menunjukkan bahwa perawat telah melakukan pengkajian keperawatan kepada pasien sesuai dengan standar asuhan keperawatan; Data Diagnosa

Keperawatan yang menunjukkan bahwa perawat telah melakukan diagnose keperawatan kepada pasien dengan baik; Data Perencanaan Keperawatan menunjukkan bahwa perawat telah melakukan perencanaan keperawatan kepada pasien dengan baik; Data Implementasi menunjukkan bahwa perawat belum melakukan implementasi keperawatan kepada pasien dengan 
baik; serta Data Evaluasi menunjukkan bahwa perawat telah melakukan evaluasi keperawatan kepada pasien dengan baik.

\section{Metode Jurnal Kedua}

Berdasarkan data yang didapat dari jurnal yang ditulis oleh Khamida dan Mastiah, didapatkan hasil sebagai berikut. Dari data karakteristik responden berdasarkan kinerja perawat, dari 39 responden menyatakan sebagian besar perawat mempunyai kinerja yang kurang; Dari data karakteristik responden berdasarkan kepuasan pasien, dari 39 responden sebagian besar mempunyai kepuasan pasien yang tidak puas;

Dari data hubungan kinerja perawat dalam memberikan asuhan keperawatan dengan kepuasan pasien rawat inap di ruang Multazam Rumah Sakit Islam Surabaya, dari 39 responden diperoleh hasil 19 responden menyatakan kinerja perawat baik, pasien merasa puas. Sedangkan 20 responden menyatakan kinerja perawat kurang, dan sebagian besar pasien merasa tidak puas. Berdasarkan uji Chi-Square, menyatakan bahwa ada hubungan antara kinerja perawat dalam memberikan asuhan keperawatan dengan kepuasan pasien rawat inap di ruang Multzam Rumah Sakit Islam Surabaya. Maka dapat disimpulkan bahwa perawat yang mempunyai kinerja baik 5 kali lebih besar mendapatkan kepuasan pasien dibandingkan dengan perawat yang mempunyai kinerja kurang.

\section{Pembahasan}

Asuhan keperawatan adalah kerangka kerja dan struktur organisasi yang kreatif untuk memberikan pelayanan keperawatan, namun asuhan keperawatan juga cukup fleksibel untuk digunakan disemua lingkup keperawatan (Potter \& Perry, 2005, p.137). Penerapan asuhan keperawatan dikatakan baik apabila perawat melaksanakan proses asuhan keperawatan dengan baik. Proses asuhan keperawatan dibagi menjadi 5 tahap, yaitu: tahap pengkajian, tahap diagnose, tahap perencanaan, tahap implementasi dan tahap evaluasi keperawatan.

\section{Tahap Pengkajian}

Pengkajian keperawatan adalah tahap awal dari proses keperawatan dan merupakan suatu proses yang sistematis dalam pengumpulan data dari berbagai sumber data untuk mengevaluasi dan mengidentifikasi status kesehatan klien. Pengkajian yang lengkap, dan sistematis sesuai dengan fakta atau kondisi yang ada pada klien sangat penting untuk merumuskan suatu diagnosa keperawatan dan dalam memberikan asuhan keperawatan sesuai dengan respon individu. Pada pengkajian ini, kita akan melakukan pengumpulan data. Data yang diperoleh ketika sedang melakukan pengkajian pada klien adalah: 1) Data Dasar, data dasar ini meliputi data umum, data demografi, riwayat keperawatan, pola fungsi kesehatan dan pemeriksaan. 2) Data Fokus, Data 
focus adalah informasi tentang status kesehatan klien yang menyimpang dari keadaan normal. Data focus dapat berupa ungkapan klien maupun hasil pemeriksaan langsung Anda sebagai seorang perawat. 3) Data Subjektif, Data yang merupakan ungkapan keluhan klien secara langsung dari klien maupun tidak langsung melalui orang lain yang mengetahui keadaan klien secara langsung dan menyampaikan masalah yang terjadi kepada Anda sebagai perawat berdasarkan keadaan yang terjadi pada klien. Untuk mendapatkan data subjektif, dilakukan anamnesis, salah satu contoh: "merasa pusing", "mual", "nyeri dada" dan lain-lain.

4) Data Objektif, Data objektif harus dapat diukur dan diobservasi, bukan merupakan interpretasi atau asumsi dari Anda, contoh: tekanan darah 120/80 mmHg, konjungtiva anemis.

Data-data tersebutpun kita ambil dari berbagai sumber. Sumber-sumber data yang dapat kita peroleh sesuai jenis data yang kita perlukan dalam pengkajian, seperti: 1) Sumber Data Primer, klien adalah sebagai sumber utama data (primer) dan Anda dapat menggali informasi yang sebenarnya mengenai masalah kesehatan klien. 2) Sumber Data Sekunder, adalah data yang diperoleh selain klien, yaitu Orang terdekat, orang tua, suami atau istri, anak, teman klien, jika klien mengalami gangguan keterbatasan dalam berkomunikasi atau kesadaran yang menurun, misalnya klien bayi atau anak-anak, atau klien dalam kondisi tidak sadar. 3) Sumber Data Lainnya, seperti catatan kesehatan terdahulu, riwayat penyakit, konsultasi, hasil pemeriksaan diagnostic, perawat lain dan kepustakaan. Adapun teknik pengumpulan data yang daoat dilakukan untuk memperoleh data sesuai dengan keperluan dan masalah yang dihadapi oleh klien, yaitu : 1) Anamnesis, suatu proses tanya jawab atau komunikasi untuk mengajak klien dan keluarga bertukar fikiran dan perasaan, mencakup keterampilan secara verbal dan non verbal, empati dan rasa kepedulian yg tinggi. 2) Observasi, pengamatan prilaku dan keadaan klien untuk memperoleh data tentang masalah kesehatan dan keperawatan klien.

3) Pemeriksaan Fisik, yang dilakukan dengan menggunakan metode atau teknik P.E. (Physical Examination) yang terdiri dari inspeksi, palpasi, perkusi, dan auskultasi.

\section{Tahap Diagnosa}

Diagnosa keperawatan merupakan penilaian klinis tentang respons individu, keluarga, atau komunitas terhadap masalah kesehatan atau proses kehidupan actual ataupun potensial sebagai dasar pemilihan intervensi keperawatan untuk mencapai hasil tempat perawat bertanggung jawab. Langkah-langkah dalam menentukan diagnose keperawatan adalah: 1) Melakukan klasifikasi data, 2) Membuat interpretasi data atas data yang sudah dikelompokkan dalam bentuk masalah keperawatan atau masalah kolaboratif, 3) Menentukan hubungan sebab akibat dari masalah keperawatan, 4) Merumuskan diagnosis 
keperawatan yang didasarkan pada pola identifikasi masalah dan kemungkinan penyebab.

\section{Tahap Perencanaan}

Karakteristik rencana tindakan keperawatan berdasarkan Standar V asuhan keperawatan antara lain: berdasarkan tujuan, merupakan alternatif tindakan terbaik.Melibatkan pasien dan keluarga, mempertimbangkan latar belakang budaya, mempertimbangkan kebujaksanaan dan peraturan yang berlaku, lingkungan, sumber daya, dan fasislitas.Menjamin rasa aman dan nyaman bagi pasien, berupa kalimat instruksi, ringkas, tegas, dan penulisan menggunakan bahasa yang mudah dimengerti dan menggunakan formulir yang baku: Tipe Rencana Tindakan Keperawatan terdiri dari: 1) Diagnostik/Observasi, adalah rencana tindakan untuk mengkaji atau melakukan observasi terhadap kemajuan klien dengan pemantauan secara langsung yang Anda lakukan secara kontinu. 2) Terapeutik/Nursing Treatment, rencana tindakan yang ditetapkan untuk mengurangi, memperbaikidan mencegah perluasan masalah.Rencana tindakan ini berupa intervensi mandiri Anda yang bersumber dari ilmu, kiat dan seni keperawatan. 3) Penyuluhan /Health Education/Pendidikan Kesehatan, adalah rencana tindakan yang Anda tetapkan bertujuan untuk meningkatkan perawatan diri kilen dengan penekanan pada partisispasi klien untuk betanggung jawab terhadap perawatan diri, terutama untuk perawatan dirumah. 4) Rujukan atau Kolaborasi atau Medical Treatment, adalah tindakan medis yang dilimpahkan kepada Anda. Rencana kolaboratif ini disesuaikan dengan masalah yang terjadi. Masalah yang bersifat kognitif, afektifdan psikomotor mungkin tidak memerlukan tindakan medis. Namun, untuk masalah yang berhubungan dengan perubahan fungsi tubuh, sering memerlukan rencana kolaboratif. Sifat rencana tindakan kolaboratif ini merupakan tugas Anda. Komponen dalam penulisan rencana tindakan keperawatan harus meliputi: komponen pertama waktu yang ditetapkan (tanggal dan jam), kedua Verb (kata kerja) dalam kalimat instruksi, ketiga Subjek yaitu siapa yang menerima tindakan keperawatan, keempat hasil merupakan hasil akhir yang dituju dari tindakan keperawatan. Kelima, target waktu merupakan periode ketika perawat melaksanakan instruksi keperawatan dan yang terakhir tanda tangan perawat.

\section{Tahap Implementasi}

Implementasi keperawatan adalah serangkaian kegiatan yang dilakukan oleh perawat untuk membantu pasien dari masalah status kesehatan yang dihadapi kestatus kesehatan yang baik yang menggambarkan kriteria hasil yang diharapkan. Proses pelaksanaan implementasi harus berpusat kepada kebutuhan klien, faktor-faktor lain yang mempengaruhi kebutuhan keperawatan, strategi 
implementasi keperawatan, dan kegiatan komunikasi. Ada tiga jenis implementasi keperawatan, yaitu: 1) Independent Implementations, adalah implementasi yang diprakarsai sendiri oleh perawat untuk membantu pasien dalam mengatasi masalahnya sesuai dengan kebutuhan, misalnya: membantu dalam memenuhi activity daily living (ADL), memberikan perawatan diri, mengatur posisi tidur, menciptakan lingkungan yang terapeutik, memberikan dorongan motivasi, pemenuhan kebutuhan psiko-sosio-kultural, dan lain-lain. 2) Interdependen/Collaborative Implementations, dalah tindakan keperawatan atas dasar kerjasama sesama tim keperawatan atau dengan tim kesehatan lainnya, seperti dokter. 3) Dependent Implementations, adalah tindakan keperawatan atas dasar rujukan dari profesi lain, seperti ahli gizi, physiotherapies, psikolog dan sebagainya, misalnya dalam hal: pemberian nutrisi pada pasien sesuai dengan diit yang telah dibuat oleh ahli gizi, latihan fisik (mobilisasi fisik) sesuai dengan anjuran dari bagian fisioterapi.

\section{Tahap Evaluasi}

Tahap evaluasi adalah penilaian dengan cara membandingkan perubahan keadaan pasien (hasil yang diamati) dengan tujuan dan kriteria hasil yang Anda buat pada tahap perencanaan. Tujuan diadakan rencana tindakan keperawatan, untuk memodifikasi rencana tindakan keperawatan serta meneruskan rencana tindakan keperawatan. Evaluasi pada dasarnya dilakukan untuk mengetahui apakah tujuan yang ditetapkan sudah dicapai atau belum. Oleh karena itu, evaluasi dilakukan sesuai dengan kerangka waktu penetapan tujuan (evaluasi hasil), tetapi selama proses pencapaian terjadi pada klien juga harus selalu harus dipantau (evaluasi proeses).Untuk memudahkan Anda mengevaluasi atau memantau perkembangan klien, digunakan komponen SOAP/ SOAPIE/SOAPIER.

\section{Penutup}

Berdasarkan hasil penilitan yang telah dilakukan oleh peniliti, terdapat kaitan antara lepuasan pasien dengan pemberian asuhan keperawatan yang baik. Alangkah baiknya jika setiap instansi kesehatan baik rumah sakit maupun klinik dan puskesmas dapat meningkatkan mutu pelayanannya, untuk mendapatkan kualitas yang baik dari masyarakat. Dan untuk mengembangkan skill para pekerja khususnya perawat pelaksana, disarankan kepada setiap rumah sakit untuuk memberikan sarana dan prasarana yang memadai, seperti mengadakan pelatihan-pelatihan pengembangan skill bagi pekerja. 


\section{Daftar Pustaka}

Astar, F., Tamsah, H., Kadir, I. (2018).

PENGARUH PELAYANAN ASUHAN

KEPERAWATAN TERHADAP KEPUASAN

PASIEN DI PUSKESMAS TAKALALA

KABUPATEN SOPPENG. Mirai: Journal Of

Management,1(2), 33-57.

(https://www.journal.stieamkop.ac.id/index.php/y ume/article/view/231)

Budiono.(2016).Modul Bahan Ajar Cetak

Keperawatan 'Konsep Dasar

Keperawatan'.Jakarta: Pusdik SDM Kesehatan

Badan Pengembangan dan Pemberdayaan Sumber

Daya Manusia Kesehatan

Dinarti, Mulyanti, Y.2017. BAHAN AJAR

KEPERAWATAN DOKUMEN

KEPERAWATAN. Jakarta : Kementerian

Kesehatan Republik Indonesia

Ivo, G., Manik, M., Simamora, O. (2018).

PENGALAMAN PERAWAT DALAM

MELAKUKAN PENGKAJIAN PASIEN BARU

DI SATU RUMAH SAKIT SWASTA DI

INDONESIA BAGIAN BARAT. Nursing

Current, 6(1), 24-33.

(https://www.google.com/url?sa=t\&source=j\&url $=$ https://pdfs.semanticscholar.org/9969/197322f40 6ef59745d4ff0c1ddf9516ed01f.pdf\&ved=2ahUK Ewiu6vj-
pKXsAhVD63MBHVm0BQoQFjABegQIAhAB

\&usg=AOvVaw2juEvW9_KDtYi4zB95LXqp)

Khamida, Mastiah. (2015). KINERJA

PERAWAT DALAM MEMBERIKAN ASUHAN

KEPERAWATAN BERPENGARUH

TERHADAP KEPUASAN PASIEN RAWAT

INAP. Jurnal Ilmiah Kesehatan 8(2), 154-161.

(https://journal2.unusa.ac.id/index.php/JHS/article $\underline{\text { /view/198/198) }}$

Kasim, M., Abdurrouf, M. (2016).

PENINGKATAN KUALITAS PELAYANAN

DAN PENDOKUMENTASIAN ASUHAN

KEPERAWATAN DENGAN METODE TIM.

NurseLine Journal, 1(1), 63-72.

(https://www.google.com/url?sa=t\&source=web\& rct=j\&url=https://media.neliti.com/media/publicat ions/197108-ID-the-increasing-service-qualityand-

nursi.pdf\&ved=2ahUKEwiZuvmwgKfsAhWUeis KHYVPBYcQFjABegQIAxAB\&usg=AOvVaw3qUQK40XUSiOCCEVfCzhE)

Simamora. R. H. (2008) The correlation of ward chief's giving direction and command and the performance of on-duty nurses at Jember dr. Subandi general hospital inpatient wards. jurnal Administrasi dan Kebijakan Kesehatan, (https://fkm.unair.ac.id/jurnal-administr)

Simamora, R. H. (2019). Development of Guidelines for Applying appropriate Patient 
Identification to Achieve Patient Safety Goal

INC2019 12th International Nursing Conference.

2019.10455 - 455 (1 pages) UCI(KEPA) : I410-

ECN-0101-2019-512-001224337

Supratti, Ashriady. (2016).

PENDOKUMENTASIAN STANDAR ASUHAN

KEPERAWATAN DI RUMAH SAKIT UMUM

DAERAH MAMUJU, INDONESIA. Jurnal

Kesehatan MANARANG, 2(1), 44-51.

(https://www.jurnal.poltekkesmamuju.ac.id/index. $\mathrm{php} / \mathrm{m} /$ article/view/13)

Widagdo, W., Kholifah, S. T. (2016). Modul

Bahan Ajar Cetak Keperawatan 'Keperawatan

Keluarga dan Komunitas'.Jakarta: Pusdik SDM

Kesehatan Badan Pengembangan dan

Pemberdayaan Sumber Daya Manusia Kesehatan

Wirdah, H.,Yusuf, M.(2016). PENERAPAN

ASUHAN KEPERAWATAN OLEH PERAWAT

PELAKSANA DI RUMAH SAKIT BANDA

ACEH. Jurnal Ilmiah Mahasiswa Fakultas

Keperawatan,1(1).

(http://jim.unsyiah.ac.id/FKep/article/view/1491)

Yeni, F. (2014). Pengaruh Pelatihan Proses

Keperawatan terhadap Dokumentasi Asuhan

Keperawatan di Puskesmas Kabupaten Agam

Propinsi Sumatera Barat. Ners Jurnal

Keperawatan, 10(1), 20-27.

(https://www.google.com/url?sa=t\&rct=j\&q=\&esr $\mathrm{c}=\mathrm{s} \&$ source $=$ web $\& \mathrm{~cd}=\& \mathrm{cad}=\mathrm{rja} \&$ uact $=8 \& \mathrm{ved}=2$ ahUKEwjuwu7S2absAhVTbSsKHbzCBogQFjA AegQIBRAC\&url=http\%3A\%2F\%2Fners.fkep.un and.ac.id\%2Findex.php $\% 2$ Fners $\% 2$ Farticle $\% 2$ Fvi
ew\%2F25\&usg=AOvVaw3yu_cAhUENnow1eNh Z8AkW) 